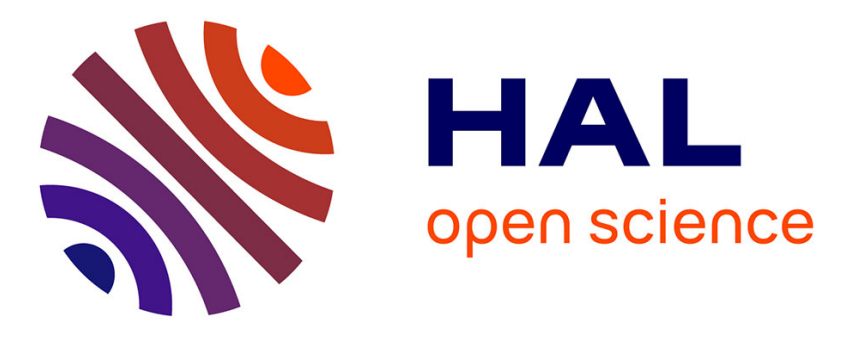

\title{
High specific surface area carbon nanotubes from catalytic chemical vapor deposition process
}

Revathi Bacsa, Christophe Laurent, Alain Peigney, Wolfgang Bacsa, Thibaud Vaugien, Abel Rousset

\section{To cite this version:}

Revathi Bacsa, Christophe Laurent, Alain Peigney, Wolfgang Bacsa, Thibaud Vaugien, et al.. High specific surface area carbon nanotubes from catalytic chemical vapor deposition process. Chemical Physics Letters, 2000, vol. 323, pp. 566-571. 10.1016/S0009-2614(00)00558-3 . hal-00942679

\section{HAL Id: hal-00942679 \\ https://hal.science/hal-00942679}

Submitted on 6 Feb 2014

HAL is a multi-disciplinary open access archive for the deposit and dissemination of scientific research documents, whether they are published or not. The documents may come from teaching and research institutions in France or abroad, or from public or private research centers.
L'archive ouverte pluridisciplinaire HAL, est destinée au dépôt et à la diffusion de documents scientifiques de niveau recherche, publiés ou non, émanant des établissements d'enseignement et de recherche français ou étrangers, des laboratoires publics ou privés. 


\section{OATAO}

\section{Open Archive TOULOUSE Archive Ouverte (OATAO)}

OATAO is an open access repository that collects the work of Toulouse researchers and makes it freely available over the web where possible.

This is an author-deposited version published in : http://oatao.univ-toulouse.fr/ Eprints ID : 10890

To link to this article : DOI:10.1016/S0009-2614(00)00558-3

URL : http://dx.doi.org/10.1016/S0009-2614(00)00558-3

\section{To cite this version :}

Bacsa, Revathi and Laurent, Christophe and Peigney, Alain and Bacsa, Wolfgang and Vaugien, Thibaud and Rousset, Abel High specific surface area carbon nanotubes from catalytic chemical vapor deposition process. (2000) Chemical Physics Letters, vol. 323 $\left(\mathrm{n}^{\circ}\right.$ 5-6). pp. 566-571. ISSN 0009-2614

Any correspondance concerning this service should be sent to the repository administrator: staff-oatao@listes-diff.inp-toulouse.fr 


\title{
High specific surface area carbon nanotubes from catalytic chemical vapor deposition process
}

\author{
R.R. Bacsa ${ }^{\text {a }}$, Ch. Laurent ${ }^{\mathrm{a}, *}$, A. Peigney ${ }^{\text {a, W.S. Bacsa }}{ }^{\mathrm{b}}$, Th. Vaugien ${ }^{\mathrm{a}}$, \\ A. Rousset ${ }^{\text {a }}$ \\ a CIRIMAT, UMR CNRS 5085 / LCMI, Centre Interuniversitaire de Recherche et d'Ingénierie des Matériaux, Université Paul-Sabatier, \\ 31062 Toulouse cedex 4, France \\ ${ }^{\mathrm{b}}$ Laboratoire de Physique des Solides de Toulouse, UMR CNRS 5477, Université Paul-Sabatier, 31062 Toulouse cedex 4, France
}

\begin{abstract}
A carbon nanotube specimen with a carbon content of $83 \mathrm{wt} . \%(95 \mathrm{vol} . \%)$ and a specific surface area equal to $790 \mathrm{~m}^{2} / \mathrm{g}$ (corresponding to $948 \mathrm{~m}^{2} / \mathrm{g}$ of carbon) is prepared by a catalytic chemical vapor deposition method. The nanotubes, $90 \%$ of which are single- and double-walled, are individual rather than in bundles. High-resolution electron microscopy shows a diameter distribution in the range $0.8-5 \mathrm{~nm}$ and Raman spectroscopy shows a high proportion of tubular carbon. Both techniques reveal a maximum in the inner wall diameter distribution close to $1.2 \mathrm{~nm}$. (C) 2000 Elsevier Science B.V. All rights reserved.
\end{abstract}

\section{Introduction}

Non-bundled carbon nanotubes (CNT) with a high specific surface area may be interesting for such applications as electromechanical actuators [1] and as media for $\mathrm{H}_{2}$ storage [2]. Ye et al. [2] have indeed reported that the $\mathrm{H}_{2}$ adsorption capacity of cut single-walled carbon nanotubes (SWNT) exceeded 8 wt. $\%$ at 40 bar at $80 \mathrm{~K}$. The increase in adsorption at high pressures was attributed to the separation of the individual SWNTs in the bundle, thus increasing the specific surface area.

In this Letter, we report the synthesis of high specific surface area CNTs by a catalytic chemical vapour deposition (CCVD) method which could be efficient for the low-cost large-scale production of CNTs. In previous works, the present laboratory has reported the synthesis of composite powders containing well-dispersed CNTs by the selective reduction in $\mathrm{H}_{2}-\mathrm{CH}_{4}$ of solid solutions between one or more transition metal oxides and a non-reducible oxide such as $\mathrm{Al}_{2} \mathrm{O}_{3}$ [3], $\mathrm{MgAl}_{2} \mathrm{O}_{4}$ [4] or $\mathrm{MgO}$ [5]. The reduction produces very small metal $(\mathrm{Fe}, \mathrm{Co}, \mathrm{Ni}$ and their alloys) nanoparticles at temperatures higher than $800^{\circ} \mathrm{C}$. The decomposition of $\mathrm{CH}_{4}$ over the freshly formed nanoparticles prevents their further growth resulting in the very strong proportion of SWNTs and double-walled carbon nanotubes (DWNT) compared to other forms of carbon. Other researchers have also reported the formation of SWNTs on metal nanoparticles supported on graphite flakes or oxide 
substrates based on $\mathrm{Al}_{2} \mathrm{O}_{3}$ and $\mathrm{SiO}_{2}$ by the catalytic decomposition of carbon monoxide [6] or hydrocarbons [7-10].

$\mathrm{MgO}$ presents the advantage over other substrates that it can be easily dissolved by a mild acid treatment. Recently, we have reported [5] the synthesis of SWNTs and DWNTs with diameters in the range $0.5-5 \mathrm{~nm}$ by the reduction of $\mathrm{Mg}_{0.9} \mathrm{Co}_{0.1} \mathrm{O}$. After the reduction, $\mathrm{MgO}$ and part of the $\mathrm{Co}$ catalyst were dissolved in $37 \% \mathrm{HCl}$ at room temperature which allowed the CNTs to be separated without damage. The carbon content was $64.5 \mathrm{wt} . \%(87.5 \%$ vol. $)$ and the remaining Co particles were either at the tube tips or encapsulated by a few graphene layers which protected it from dissolution [5]. In order to increase the yield and the purity, we have increased the specific surface area of the precursor oxide and varied its cobalt content. Specimens containing 83 wt.\% carbon (i.e. 95 vol.\%) and with a specific surface area of $790 \mathrm{~m}^{2} / \mathrm{g}$ (corresponding to 948 $\mathrm{m}^{2} / \mathrm{g}$ of carbon) are obtained in the present work.

\section{Experimental}

$\mathrm{Mg}_{1-x} \mathrm{Co}_{x} \mathrm{O} \quad(x=0.025,0.05,0.10,0.15$ and $0.20)$ solid solutions were prepared by combustion synthesis [11]. The experimental conditions were adjusted to prepare monophased products with a high specific surface area. Nitrates of magnesium and cobalt in the appropriate ratios were mixed with urea and the mixture was introduced into a furnace maintained at $550^{\circ} \mathrm{C}$, producing the desired powders in less than $5 \mathrm{~min}$. The formation of a single phase was verified by X-ray diffraction and the specific surfaces areas were found to be in the range 30-40 $\mathrm{m}^{2} / \mathrm{g}$. These powders were placed in a furnace under a flowing $\mathrm{H}_{2}-\mathrm{CH}_{4}$ atmosphere $(18 \mathrm{~mol} . \%$ $\left.\mathrm{CH}_{4}, 250 \mathrm{sccm}\right)$ and were heated at $1000^{\circ} \mathrm{C}$. On reaching this temperature, the powders were cooled down to room temperature. The so-obtained CNT$\mathrm{Co}-\mathrm{MgO}$ composite powders (noted R2.5, R5, ... and $\mathrm{R} 20$ in the following) were dropped into $\mathrm{HCl}$ aqueous solution ( $37 \%$, room temperature) in order to extract the CNTs by dissolution of $\mathrm{MgO}$ and part of Co. The residues containing the CNTs were separated by centrifugation and washed several times in water and dried at $80^{\circ} \mathrm{C}$. The resulting materials will be called the extracted products and noted ER2.5, ER5, ... and ER20.

The composite powders were observed by scanning electron microscopy (SEM). A parameter $(\Delta S)$ representing the quantity of CNTs in these powders was derived from BET specific surface area measurements as described elsewhere [3,4]. The carbon content in the composite powders $\left(C_{\mathrm{n}}\right)$ and in the extracted products $\left(C_{\mathrm{e}}\right)$ was determined by flash combustion. The BET specific surface areas of the extracted products $\left(S_{\mathrm{e}}\right)$ were determined by $\mathrm{N}_{2}$ adsorption at liquid $\mathrm{N}_{2}$ temperature. Selected specimens were studied by high resolution transmission electron microscopy (HREM) and Raman spectrometry. The Raman spectra were recorded using a Micro-Raman set-up (DILORXY), back-scattering geometry and at $488 \mathrm{~nm}(3-5 \mathrm{~mW})$. The sample was placed on a bilayer substrate to enhance the Raman signal or alternatively on a microscope slide.

\section{Results and discussion}

The carbon content in the composite powder $\left(C_{\mathrm{n}}\right)$ increases with cobalt content. A plateau is observed between R5 and R10 (Fig. 1). $\Delta S$ follows a similar evolution, the plateau being less marked (Fig. 1). Its origin remains unclear. SEM observations (images

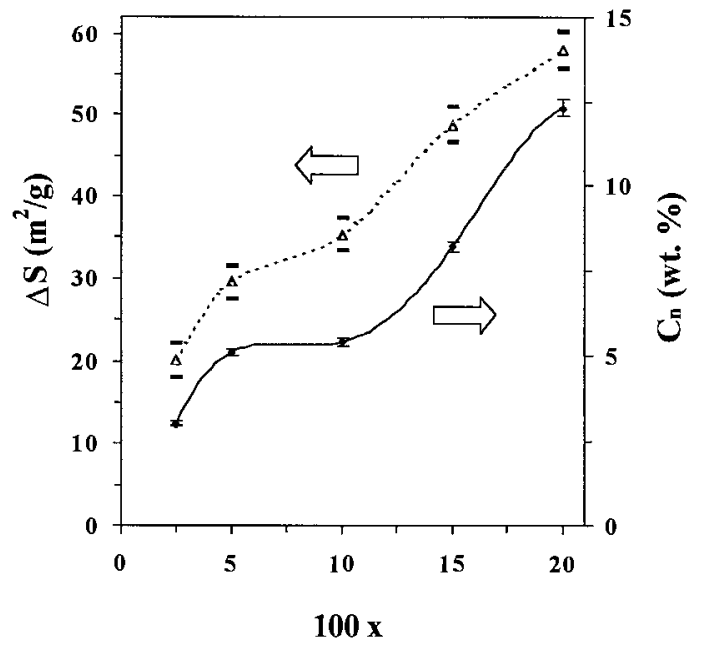

Fig. 1. Carbon content $\left(C_{\mathrm{n}}\right)$ in the CNTs-Co-MgO powders and parameter $\Delta S$ representing the quantity of CNTs versus the cobalt content $\left(x\right.$ in $\left.\mathrm{Mg}_{1-x} \mathrm{Co}_{x} \mathrm{O}\right)$ of the precursor oxide. 
not shown) confirm that the quantity of CNTs increases with cobalt content, but it was noted that individual CNTs rather than bundles are obtained for lower cobalt contents. However, this is difficult to quantify. The carbon content in the extracted products $\left(C_{\mathrm{e}}\right)$ decreases with increase in cobalt content, quite sharply between ER5 and ER10 (Fig. 2). This reveals the increased presence of Co-containing carbon nanocapsules which resist dissolution in $\mathrm{HCl}$. The maximum purity is obtained for ER2.5 and ER5 (ca. 83 wt.\%, i.e. ca. 95 vol.\% assuming a density of $2.26 \mathrm{~g} / \mathrm{cm}^{3}$ for carbon). Comparing with the values of $\Delta S$, one can conclude that an optimum of yield and purity is obtained for ER5.

$S_{\mathrm{e}}$ decreases from $790 \mathrm{~m}^{2} / \mathrm{g}$ for ER2.5 to 350 $\mathrm{m}^{2} / \mathrm{g}$ for ER20 (Fig. 2). A part of this decrease is due to the increasing cobalt content in the ER materials. Considering that all remaining Co particles are within carbon nanocapsules and at the tube tips and that the cobalt particles do not contribute to the surface area, the specific surface area per gram of carbon is obtained by calculating the ratio $\mathrm{S}_{\mathrm{e}} / C_{\mathrm{e}}$. A maximum value of $948 \mathrm{~m}^{2} / \mathrm{g}$ of carbon is thus obtained for ER2.5. These values are much higher than those previously reported $[2,12,13]$. Ye et al. [2] measured $285 \mathrm{~m}^{2} / \mathrm{g}$ for a sample of bundles of SWNTs. Inoue et al. [12] measured $178 \mathrm{~m}^{2} / \mathrm{g}$ for a powder of commercial multiwalled carbon nanotubes

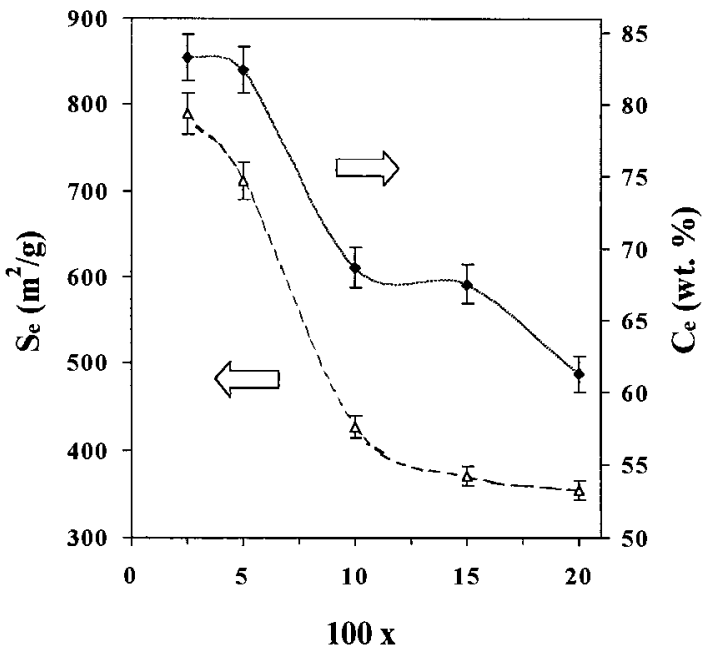

Fig. 2. Carbon content $\left(C_{\mathrm{e}}\right)$ and specific surface area $\left(S_{\mathrm{e}}\right)$ of the extracted products versus the cobalt content $\left(x\right.$ in $\left.\mathrm{Mg}_{1-x} \mathrm{Co}_{x} \mathrm{O}\right)$ of the precursor oxide.
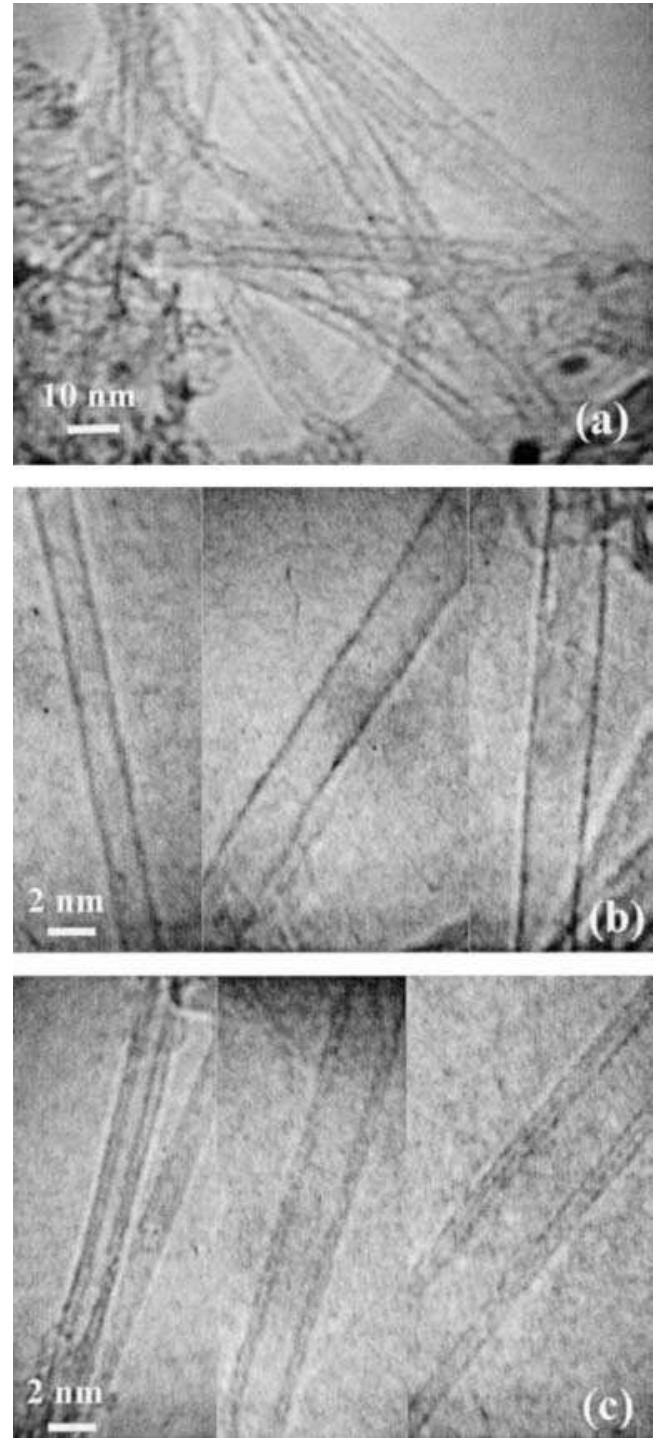

Fig. 3. High resolution transmission electron microscopy images of the extracted product (ER5).

(MWNTs, Hyperion Catalysis Int. Co.). Hernadi et al. [13] prepared mixtures of SWNTs and MWNTs by CCVD on Co-zeolite catalyst. The measured values were $653 \mathrm{~m}^{2} / \mathrm{g}$ for specimens where the zeolite was removed by HF treatment and only $312 \mathrm{~m}^{2} / \mathrm{g}$ after a further purification by $\mathrm{KMnO}_{4}$ oxidation.

Fig. 3 shows HREM images obtained on ER5. Individual CNTs, thin bundles and Co particles (dark spots) are shown in Fig. 3a. Amorphous carbon is not observed. The SWNTs have diameters in the 
range 1-3 nm (Fig. 3b). The external diameter of DWNTs is generally in the same range whereas CNTs with three walls are markedly larger (Fig. 3c). Owing to the great length of the CNTs (tens or hundreds of $\mu \mathrm{m}$ ), tube tips are seldom observed, but all those observed appear to be closed showing that the CNTs are not opened or damaged by the mild acid treatment. The number of walls (Fig. 4a) as well as the inner and outer diameters (Fig. 4b) of 60 isolated CNTs were measured on HREM images similar to those shown in Fig. 3. Almost $90 \%$ of the CNTs are SWNTs or DWNTs (Fig. 4a). More than $90 \%$ of the present CNTs have a diameter not larger than $3 \mathrm{~nm}$. Measurement over different areas of the sample showed that most Co particles have a diameter of 2-3 nm and only some are larger $(6-10 \mathrm{~nm})$. It was difficult to determine the nature of the carbon nanocapsules surrounding them. It is inferred that there are made up of only a few carbon layers.

The Raman spectrum of ER5 (Fig. 5) shows an intense band at $1580 \mathrm{~cm}^{-1}$ due to the optical phonons in curved graphite sheets. The curvature induces a
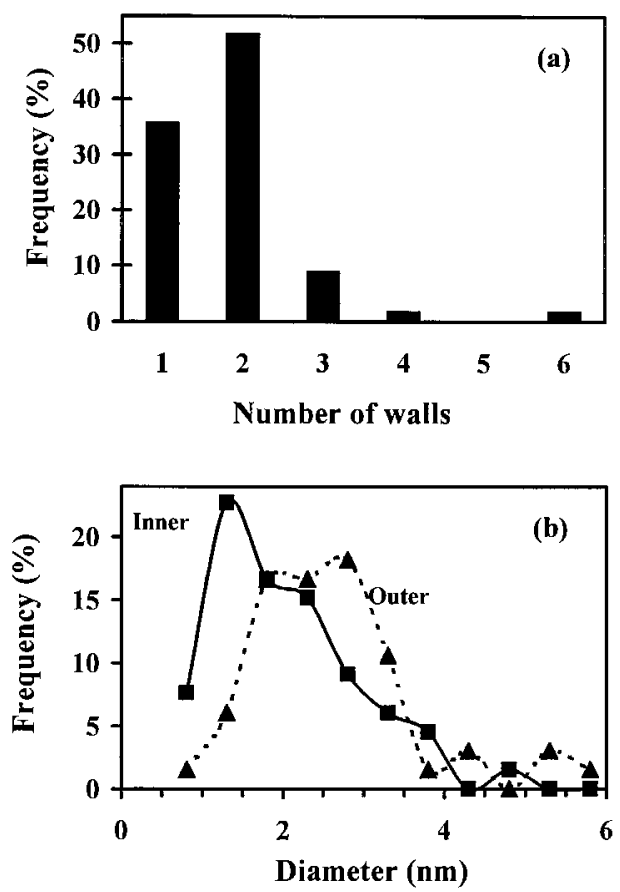

Fig. 4. Distribution of the number of walls (a) and of the inner and outer diameters (b) of the CNTs in ER5 using data from HREM images.

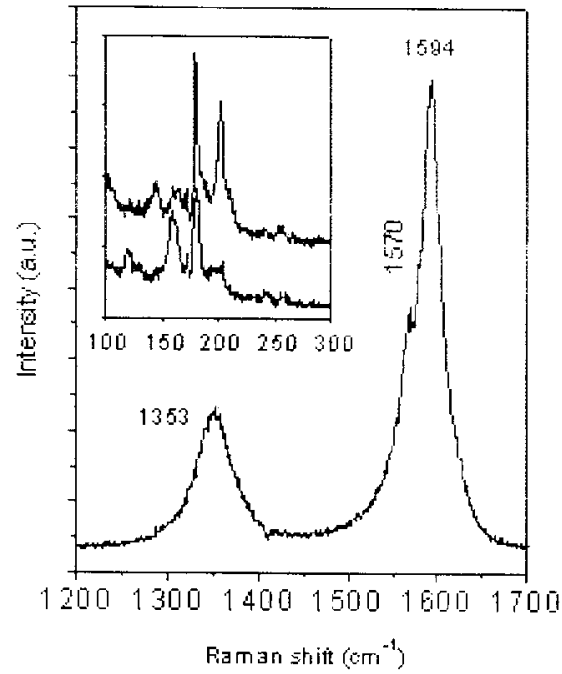

Fig. 5. Raman spectra at $488 \mathrm{~nm}$ excitation of carbon nanotubes (ER5) shows a band due to optical phonons in curved graphite sheets $\left(1580 \mathrm{~cm}^{-1}\right)$ and defect induced scattering $\left(1360 \mathrm{~cm}^{-1}\right)$. The inset shows two spectra on different locations on the sample showing low frequency modes sensitive to tube diameter corresponding to tube diameters of 1.1-1.9 nm.

splitting of the in-plane degenerate optical mode in graphite resulting in two major bands (1570 and $\left.1594 \mathrm{~cm}^{-1}\right)[14,15]$. The band observed at 1353 $\mathrm{cm}^{-1}$ is about 3 times less intense and is due to the presence of defects in the graphite sheets. This band is particularly intense in samples which contain spherical carbon shells containing a large number of defects. In the present case, the defect band indicates the presence of disordered forms of carbon possibly related to spherical carbon shells (nanocapsules) or to the incomplete formation of a second or a third layer on the SWNTs. In the acoustic phonon region (inset in Fig. 5), we observe two narrow bands below $300 \mathrm{~cm}^{-1}$ corresponding to the radial breathing mode of the tube. Its frequency is inversely proportional to the tube diameter and can be used to obtain an accurate measure of the average tube diameter of the probe volume which is typically several $\mu \mathrm{m}^{3}$. The two spectra correspond to different areas of the same material. The two narrow peaks observed correspond to diameters of 1.11 and $1.245 \mathrm{~nm}$. These values are in agreement with the peak of the inner diameter distribution as observed by HREM (Fig. 4a). However, the intensity of the Raman peaks and to some extent, the position of the observed spectral bands 
depend on the wavelength of the incident beam which are related to the electronic properties of the medium. Therefore, the presence of other diameter tubes in this range cannot be ruled out. This is also be in agreement with HREM observations. The Raman spectra show the high purity of the material. No scattering due to amorphous forms of carbon is observed.

In a previous work [16], we have calculated the geometrical specific surface areas of individual CNTs and bundles of CNTs versus the tube diameter, the number of walls and the number of CNTs in a bundle. The specific surface area decreases by a factor of 3 as the number of walls is changed from 1 to $5\left(1315\right.$ to ca. $\left.400 \mathrm{~m}^{2} / \mathrm{g}\right)$ and also decreases when there are more CNTs in a bundle. The specific surface area for individual CNTs with a diameter distribution of $0.8-3 \mathrm{~nm}$ and which are predominantly SWNTs and DWNTs (Fig. 4) is calculated to be in the range $900-1000 \mathrm{~m}^{2} / \mathrm{g}$. This value is in good agreement with the present experimental value (948 $\left.\mathrm{m}^{2} / \mathrm{g}\right)$ showing that a large fraction of the CNTs are individual tubes. Although HREM observations seem to indicat that the CNTs are not open, it cannot be entirely ruled out that some indeed are open and that their inner surface area contributes to the experimental value.

Using a starting oxide with a high specific surface area favors the nucleation and growth of surface Co particles, as opposed to intragranular particles. Increasing the cobalt content also produces more surface Co particles, which give more CNTs $(\Delta S$, Fig. 1). However, a too high surface density of Co particles favors the coalescence and the formation of encapsulated Co particles, which eventually hampers the purification $\left(C_{\mathrm{e}}\right.$, Fig. 2). Very high specific surface areas are observed when using low cobalt contents $\left(S_{\mathrm{e}}\right.$, Fig. 2). The decrease of $S_{\mathrm{e}}$ for higher cobalt contents could be due either to the increasing presence of carbon nanocapsules or to a bundling effect as observed above. The specific surface area of the nanocapsules is equivalent to that of CNTs with the same diameter and number of layers. However, a given catalyst particle produces either a CNT or a nanocapsule and one can consider that the contribution to the surface area (in $\mathrm{m}^{2}$ ) by the nanocapsule is negligible compared to that of the CNT which has a very high aspect ratio. Therefore, the contribution of the nanocapsules to the total surface area is likely to be small. Thus, the decrease of $S_{\mathrm{e}}$ is more likely related to the increase of the diameter of the bundles.

\section{Conclusions}

A CNTs specimen with a carbon content of 83 wt.\% (95 vol.\%) and a specific surface area equal to $790 \mathrm{~m}^{2} / \mathrm{g}$ (corresponding to $948 \mathrm{~m}^{2} / \mathrm{g}$ of carbon) has been synthesized. The specific surface area is the highest reported value to the best of our knowledge. The selective reduction in $\mathrm{H}_{2}-\mathrm{CH}_{4}$ of $\mathrm{Mg}_{1-x} \mathrm{Co}_{x} \mathrm{O}$ produces $\mathrm{CNTs}-\mathrm{Co}-\mathrm{MgO}$ powders. $\mathrm{MgO}$ and a fraction of the Co particles are dissolved by a mild acid treatment that does not damage the CNTs. More than $90 \%$ of the CNTs are SWNTs and DWNTS with diameters in the range $0.8-5 \mathrm{~nm}$. Decreasing the cobalt content in the oxide precursor produces less CNTs but also much less encapsulated Co particles, which favors the purification. An advantage of the CCVD method is that it produces individual rather than bundled CNTs. Work is in progress to investigate the opening of the CNTs and to further improve the purity.

\section{Acknowledgements}

The authors thank Dr. E. Flahaut for discussions and Mr. L. Datas for his assistance in the HREM observations, which have been performed at the Service Commun de Microscopie Electronique à Transmission - Université Paul-Sabatier.

\section{References}

[1] R.H. Baughman, C. Cui, A.A. Zakhidov, Z. Iqbal, J.N. Barisci, G.M. Spinks, G.G. Wallace, A. Mazzoldi, D. De Rossi, A.G. Rinzler, O. Jaschinski, S. Roth, M. Kertesz, Science 284 (1999) 1340.

[2] Y. Ye, C. Ahn, C. Witham, B. Fultz, J. Liu, A.G. Rinzler, D. Colbert, K.A. Smith, R.E. Smalley, Appl. Phys. Lett. 74 (1999) 2307.

[3] A. Peigney, Ch. Laurent, F. Dobigeon, A. Rousset, J. Mater. Res. 12 (1997) 613

[4] E. Flahaut, A. Govindaraj, A. Peigney, Ch. Laurent, A. Rousset, C.N.R. Rao, Chem. Phys. Lett. 300 (1999) 236. 
[5] E. Flahaut, A. Peigney, Ch. Laurent, A. Rousset, J. Mater. Chem. 10 (2000) 249.

[6] H. Dai, A.G. Rinzler, P. Nikolaev, A. Thess, D.T. Colbert, R.E. Smalley, Chem. Phys. Lett. 260 (1996) 471.

[7] J.H. Hafner, M.J. Bronikowski, B.R. Azamian, P. Nikolaev, A.G. Rinzler, D.T. Colbert, K.A. Smith, R.E. Smalley, Chem. Phys. Lett. 296 (1998) 195.

[8] J. Kong, A M. Cassell, H. Dai, Chem. Phys. Lett. 292 (1998) 567.

[9] A.M. Cassell, J.A. Raymakers, J. Kong, H. Dai, J. Phys. Chem. 103 (1999) 6484.

[10] J.F. Colomer, G. Bister, I. Willems, Z. Konya, A. Fonseca, G. Van Tendeloo, J.B. Nagy, Chem. Commun., 1999, p. 1343.

[11] K.C. Patil, Bull. Mater. Sci. 16 (1993) 533.
[12] S. Inoue, N. Ichikuni, T. Susuki, T. Uematsu, K. Kaneko, J. Phys. Chem. B 102 (1998) 4689.

[13] K. Hernadi, A. Fonseca, J.B. Nagy, D. Bernaerts, A. Fudala, A.A. Lucas, Zeolites 17 (1996) 416.

[14] A.M. Rao, E. Richter, S. Bandow, B. Chase, P.C. Eklund, K.A. Williams, S. Fang, K.R. Subbaswamy, M. Menon, A. Thess, R.E. Smalley, G. Dresselhaus, M.S. Dresselhaus, Science 257 (1997) 187.

[15] W.S. Bacsa, C.W. Walter, S. Awasallah, S. McGinnis, R.S. Ruoff, in: K.M. Kadish, R.S. Ruoff (Eds.), Advances in the Chemistry and Physics of Fullerenes, The Electrochemical Society Inc. 3 (1996) 749.

[16] A. Peigney, Ch. Laurent, E. Flahaut, A. Rousset, Carbon (accepted). 